\title{
Intradermal Sterile Water Injection versus Epidural Bupivacaine in Painless First Stage of Labor
}

\author{
Saeed Mohammed Faied, Abdalla Mohammed Abdalla, \\ Ahmed Youssef Mohammed Youssef * \\ Anesthesiology and Intensive Care Department, Faculty of Medicine, Al-Azhar University \\ * Corresponding author: Ahmed Youssef Mohammed Youssef, E-mail: \\ medinfo20005000@gmail.com
}

\begin{abstract}
Background: Many women have moderate to severe low back pain during labor. It has been shown that injection of sterile water can reduce the pain of $1^{\text {st }}$ stage. This method is very cheap, easy to learn and can be used as alternative method for reducing the labor pain.

Objectives: The aim of this study was to compare the effectiveness, women satisfaction safety and safety of intradermal sterile water injection and epidural bupivacaine in decreasing the pain of $1^{\text {st }}$ stage of labor. Patients and Methods: After approval of Institutional Ethical Committee and obtaining written informed consent from eligible parturient women, 120 healthy parturient divided into 3 groups. 1st group epidural bupivacaine plus fentanyl, Initiated with $10 \mathrm{ml}$ of bupivacaine $0.125 \%$ with 2 micrograms/ $\mathrm{ml}$ of fentanyl and maintained with $10 \mathrm{ml} / \mathrm{h}$ of the same mixture. 2nd group intradermal injection of sterile water $0.1 \mathrm{ml}$, while 3rd group intradermal injection of $0.1 \mathrm{ml}$ normal saline.

Results: The study reported good pain relief in epidural and sterile water group compared to normal saline group. Pain relief was comparable in both the epidural and sterile water group. Complications were more demonstrated in epidural compared to the sterile water and the normal saline groups. A good maternal satisfaction in epidural and sterile water group with no satisfaction in the normal saline group.

Conclusion: The evidence from this study suggests that sterile water injections are safe and effective method for relieving pain of the $1^{\text {st }}$ stage of labor similar to epidural bupivacaine analgesia.
\end{abstract}

Keywords: Sterile Water, Labor Pain.

\section{INTRODUCTION}

Normal vaginal delivery pain is drastically hard to tolerate, especially during the first stage. Some women experience abdominal pain, some others have lower back pain, and some have both types. Although the pain of giving birth usually appears with the onset of uterine contractions, sometimes lower back pain is also experienced in the intervals between uterine contractions. About $30 \%$ of women suffer from constant back pain simultaneously to contractions and apparently lack of rest in the intervals between contractions makes tolerance of pain much more difficult ${ }^{(\mathbf{1})}$.

Visual analogue score that usually used as scoring system for pain assessment in different studies, is used also for assessment of labor pain ${ }^{(2)}$.

Recently, epidural analgesia has become one of the most frequently used analgesic techniques for birth. The advantage of this technique is its ability to provide analgesia during labor as well as excellent anesthesia for delivery, as it is titrated to maintain the patient's sense of touch and motor ability, facilitating participation in the birth process. Epidural analgesia reduces pain-induced maternal hyperventilation during labor, preventing left shift of the hemoglobin dissociation curve in the mother, which can have detrimental effects on fetal hemoglobin saturation ${ }^{(3)}$. Stress intensity is influenced by numerous factors such as previous pain experiences, education, culture, expectations, environmental factors and support from caregivers (4). Some draw backs are linked with regional analgesia techniques as pain at the puncture site, fear of needles and recall of the procedure ${ }^{(5)}$.

Stress response leads to release of catecholamines and other vasopressors. At full term, uterine vasculature is maximally dilated, but still responds to these vasopressors causing uterine vasoconstriction and decrease the uterine and placental blood flow which adversely affect the neonates ${ }^{(3)}$. Therefore, the prevention from maternal stress is potentially important. This can be prevented by giving patients detailed information 
ejhm.journals.ekb.eg

about their operation and with preoperative pharmacological medications ${ }^{(\boldsymbol{6})}$.

The use of epidural analgesia is not without consequences and is associated with increased frequency of instrumental delivery (forceps or vacuum) and some degree of motor weakness in the parturient ${ }^{(7)}$.

Sterile water injected lateral to the lumbosacral spine is a simple approach to ameliorate the visceral pain of labor including that of low back. This approach is easy to administer, inexpensive, has minor side-effects and can be administered without care specialist. Intracutaneous sterile water injection is associated with acute pain that lasts for 30 seconds but as the pain subsides so does the visceral referred pain of low back. The effect begins quickly and has been shown to be effective for 2 to 3 hours, long after the acute pain of the injection has subsided (5). Physiologically the hypotonic, sterile water does not act as a local anesthetic and does not directly inhibit the visceral pain fibres. In fact, sterile water will cause firing of the $\mathrm{C}$ fibres as well as A-delta fibres normally associated with somatic pain. The leading hypothesis explaining the efficacy of sterile water is that the firing of A-delta fibres overwhelms the visceral pain input from $\mathrm{C}$ fibres such that the visceral pain is not noticeable. This hypothesis relies somewhat on gate control theory of pain although it may also be that intracutaneous sterile water leads to endorphin release similar to that found in acupuncture ${ }^{(8)}$.

The aim of our study was to compare the effectiveness, safety and women satisfaction of intradermal sterile water injection and epidural bupivacaine to decrease pain in $1^{\text {st }}$ stage of labor.

\section{PATIENTS AND METHODS}

The study was conducted in the Obstetrics Department of Al-Azhar University Hospitals "Al-Hussein and Bab-Al-Shaarya", Cairo, Egypt, from December 2018 till September 2019.

\section{Patients:}

After informing the women about the advantages and disadvantages of each method and discussing with them, which way is suitable for each one.

One hundred and twenty parturients were enrolled in this study. Parity in the first group was $15 / 40$ primipara \& $25 / 40$ multipara (less than 5 deliveries), while in the second group, parity was $11 / 40$ primipara \& $29 / 40$ multipara and in third group, it was $13 / 40$ primipara \& $27 / 40$ Multipara respectively.
Patients randomly assigned to either of three groups (40 patients each).

Group I: Epidural with bupivacaine plus fentanyl

Group II: Intradermal sterile water

Group III: Intradermal normal saline.

\section{Ethical approval and written informed consent:}

An approval of the study was obtained from Al- Azhar University Academic and Ethical Committee. Every patient signed an informed written consent for acceptance of the operation.

\section{Inclusion criteria}

1. Request for analgesia, only patient how needed analgesia.

2. Null parity

3. Age 25-35 years,

4. Body mass index $<30 \mathrm{~kg}$ per square meter,

5. American anathesiology association ASA I or II,

6. Gestational age $>37$ weeks.

7. Single fetus in cephalic presentation.

8. Normal fetal heart rate and true labor with cervical dilatation $>4 \mathrm{~cm}$.

\section{Exclusion criteria}

1. Patients receiving analgesia prior to enrolment.

2. Presence of complicated pregnancies with hypertension, diabetes mellitus, neurological disease, recent hemorrhage, preeclampsia, eclampsia.

3. Suspicion of fetal malformation and intrauterine growth retardation.

4. Fever and history of allergy to local anesthetics.

5. Body mass index above 35 .

6. ASA class III

7. Gestational age less than 37 weeks.

8. Any patient turned to caesarian section.

\section{Prepartum evaluation:}

Pre labor maternal assessment to fulfill patients criteria for study by full history taking physical examination including chest and heart examination routine labs was done as ( complete blood count, random blood sugar, INR)

\section{Methods:}

Study protocol was explained to the patients taking their consent. Explanation of visual analog scale (VAS) scoring system for all patients. Patient arterial blood pressure was recorded and $\mathrm{O} 2$ saturation and heart rate were recorded by automatic monitor with pulse oximetry. Wide bore 18 gauge cannulae was inserted for receiving ringer solution 
ejhm.journals.ekb.eg

\section{Study groups:}

\section{Group I: Epidural (E)}

Each parturient was preloaded with $500 \mathrm{ml}$ of lactated ringer solution before the initiation of epidural analgesia. A 20 gauge epidural catheter (prefix epidural set) was inserted under aseptic precautions in the lateral position at L3-L4 or L4L5 interspaces with the loss of resistance to saline technique. The epidural catheter was then secured and the parturient placed in the supine position with left uterine displacement with the head of the bed elevated $20-30$ degrees. $3 \mathrm{ml}$ test dose of $2 \%$ lidocaine containing epinephrine $15 \mu \mathrm{gm}$ used to exclude intravascular or subarachnoid placement. Epidural analgesia will be initiated with a $15 \mathrm{ml}$ bolus of bupivacain $0.125 \%$ with $2 \mu \mathrm{gms} / \mathrm{ml}$ of fentanyl and maintained with $10 \mathrm{ml} / \mathrm{hr}$ of same mixture. This infusion maintained throughout the first stage of labor. Maternal blood pressure recorded every 5 minutes for 30 minutes after initiation of epidural analgesia and then every 15 min. Until delivery.

\section{Group II- Intradermal sterile water injection (S.W.)}

Parturient of this group received four intradermal injections of sterile water in the lumbo-sacral region (Michael's rhomboid).

1. The volume of each injection was $0.1 \mathrm{ml}$. The injections administered using $1 \mathrm{ml}$ insulin syringe with fine needle ( 30 gauges). The injections were given during contraction. The treatment was repeated every $90 \mathrm{~min}$ intradermal injection of sterile water $0.1 \mathrm{ml}$, in the lumbo-sacral region (Michael's rhomboid).

Group III - Intradermal normal saline injection: patients received injections of $0.1 \mathrm{ml}$ isotonic saline in the same region using an insulin needle.

\section{The following parameters were assessed:}

1. Demographic data include (age in years, gestationl age in weeks and BMI).

2. Mode of delivery incidence if vaginal or instrumental delivery.

3. Pain assessment: pain was assessed with $10 \mathrm{~cm}$ visual analogue scale with 0 representing no pain and 10 being the worst pain imaginable, pain assessed before initiation of analgesia and at 5,10,15, $30 \mathrm{~min}$ then every $30 \mathrm{~min}$.

4. Maternal blood pressure and heart rate were recorded using monitor with automatic noninvasive intermittent blood pressure monitoring and pulse oximeter was recorded before starting and at $5,10,15,30$ then every 30 min.

5. Side effects of epidural administration, intradermal sterile water injection and intradermal saline injection.

6. Degree of parturient satisfaction:

Overall satisfaction with analgesia will be assessed by using a 4-point verbal scale ranging from excellent to poor satisfaction:
A. Excellent satisfaction.
B. Good satisfaction.
C. Fair satisfaction.
D. Poor satisfaction.

\section{Statistical analysis:}

Recorded data were analyzed using the statistical package for social sciences, version 20.0 (SPSS Inc., Chicago, Illinois, USA). Quantitative data were expressed as mean \pm standard deviation (SD). Qualitative data were expressed as frequency and percentage. The following tests were done:

- Independent-samples t-test of significance was used when comparing between two means.

- Chi-square $\left(\mathrm{x}^{2}\right)$ test of significance was used in order to compare proportions between two qualitative parameters.

- The confidence interval was set to $95 \%$ and the margin of error accepted was set to $5 \%$. The pvalue was considered significant as the following:

- Probability (P-value)

- P-value $<0.05$ was considered significant.

- P-value < 0.001 was considered as highly significant.

- P-value > 0.05 was considered insignificant.

\section{RESULTS}

A total of 120 parturients were eligible for our procedure. They were randomized into the epidural, sterile water and normal saline groups, 40 parturients for each. No statistically significant difference was found between the three groups, regarding the patients' demographic characteristics as shown in table (1).

Table (1): Characteristics and demographic data expressed as mean \pm SD. 
ejhm.journals.ekb.eg

\begin{tabular}{|c|c|c|c|c|c|c|c|c|}
\hline \multirow{3}{*}{\multicolumn{2}{|c|}{$\begin{array}{l}\text { Demographic character and mode } \\
\text { of delivery }\end{array}$}} & \multicolumn{6}{|c|}{ GROUPS } & \multirow{3}{*}{$\begin{array}{l}\text { P- } \\
\text { VALUE }\end{array}$} \\
\hline & & \multicolumn{2}{|c|}{ Group E } & \multicolumn{2}{|c|}{ GROUP SW } & \multicolumn{2}{|c|}{ GROUP NS } & \\
\hline & & Mean & SD & Mean & SD & Mean & SD & \\
\hline & AGE & 29.8 & \pm 4.8 & 28.65 & \pm 4.8 & 27.05 & \pm 4.8 & $>0.05$ \\
\hline & BMI & 27.32 & \pm 1.7 & 27.28 & \pm 1.8 & 27.08 & \pm 1.6 & $>0.05$ \\
\hline \multicolumn{2}{|r|}{ GESTATION } & 39.6 & \pm 1.2 & 39.62 & \pm 1.2 & 39.58 & \pm 1.1 & $>0.05$ \\
\hline \multirow{4}{*}{$\begin{array}{l}3 \\
0 \\
0 \\
0 \\
0 \\
0 \\
0 \\
\varnothing \\
\\
0 \\
\end{array}$} & VAGINAL (\%) & \multicolumn{2}{|c|}{$92.50 \%$} & \multicolumn{2}{|c|}{$97.50 \%$} & \multicolumn{2}{|c|}{$97.50 \%$} & \multirow[t]{4}{*}{$>0.05$} \\
\hline & Number of cases & \multicolumn{2}{|c|}{$\mathrm{n}(37)$} & \multicolumn{2}{|c|}{$\mathrm{n}(39)$} & \multicolumn{2}{|c|}{$\mathrm{n}(39)$} & \\
\hline & INSTRUMENTAL (\%) & \multicolumn{2}{|c|}{$7.50 \%$} & \multicolumn{2}{|c|}{$2.50 \%$} & \multicolumn{2}{|c|}{$2.50 \%$} & \\
\hline & Number of cases & \multicolumn{2}{|c|}{$\mathrm{n}(3)$} & \multicolumn{2}{|c|}{$\mathrm{n}(1)$} & \multicolumn{2}{|c|}{$\mathrm{n}(1)$} & \\
\hline
\end{tabular}

Our study showed significant difference between all groups, regarding pain relief as shown in table (2). There was a significant decrease in pain score after $5 \mathrm{~min}$ in sterile water group compared to other groups. Furthermore, there was significant decrease in pain score in epidural group compared to normal saline control group after 15 minutes while it was not significant after 5 minutes.

Table (2): Comparison between groups according to visual analogue pain score

\begin{tabular}{|c|c|c|c|c|c|c|c|}
\hline \multirow{2}{*}{\begin{tabular}{|l|} 
Groups \\
Vas
\end{tabular}} & \multicolumn{2}{|c|}{ group I } & \multicolumn{2}{|c|}{ group II } & \multicolumn{2}{|c|}{ group III } & \multirow{2}{*}{$\begin{array}{c}\text { P- } \\
\text { VALUE }\end{array}$} \\
\hline & Mean & $\begin{array}{c}\text { Std. } \\
\text { Deviation }\end{array}$ & Mean & $\begin{array}{c}\text { Std. } \\
\text { Deviation }\end{array}$ & Mean & $\begin{array}{c}\text { Std. } \\
\text { Deviation }\end{array}$ & \\
\hline Pre injection & 5.93 & \pm 1.207 & 6.25 & \pm 1.256 & 5.85 & \pm 1.122 & $<0.005$ \\
\hline $5 \min$ & 3.83 & \pm 1.615 & 1.78\#en & \pm 1.459 & $6.05^{*} \mathrm{w}$ & \pm 1.28 & 0.005 \\
\hline $10 \mathrm{~min}$ & 4.55 & \pm 1.797 & $1 \#$ en & \pm 0.847 & $5.73 * \mathrm{~W}$ & \pm 1.261 & $<0.005$ \\
\hline $15 \mathrm{~min}$ & $1.47 \# \mathrm{n}$ & \pm 0.96 & $0.82 \# n$ & \pm 0.844 & $5.93^{*} \mathrm{ew}$ & \pm 1.207 & $<0.005$ \\
\hline $30 \mathrm{~min}$ & $0.55 \# \mathrm{n}$ & \pm 0.504 & $0.88 \# n$ & \pm 0.853 & $6 * \mathrm{ew}$ & \pm 1.301 & $<0.005$ \\
\hline $60 \mathrm{~min}$ & $0.55 \# \mathrm{n}$ & \pm 0.504 & $0.82 \# n$ & \pm 0.874 & $5.78 * \mathrm{ew}$ & \pm 1.23 & $<0.005$ \\
\hline $90 \mathrm{~min}$ & $0.43 \# n$ & 0.501 & 0.8 & \pm 0.844 & $6.03 *$ & \pm 1.291 & $<0.005$ \\
\hline $120 \mathrm{~m}$ & $0.48 \# n$ & \pm 0.506 & 1.0 & \pm 0.815 & 5.93 & \pm 1 . & $<0.005$ \\
\hline $150 \mathrm{~min}$ & $0.55 \# \mathrm{n}$ & \pm 0.504 & $0.88 \# n$ & \pm 0.853 & $5.85^{*} \mathrm{ew}$ & \pm 1.189 & $<0.005$ \\
\hline $180 \mathrm{~min}$ & $0.73 \#$ n & \pm 0.679 & $1.00 \# \mathrm{n}$ & \pm 0.847 & $5.93^{*} \mathrm{ew}$ & \pm 1.207 & $<0.005$ \\
\hline \multicolumn{8}{|c|}{$\begin{array}{l}\text { Data expressed as mean } \pm \text { SD. Group I (Epidural group). Group II (Sterile water group). Group III (Normal } \\
\text { saline group) } \\
(*) \text { significant higher compared to other group. }(\#) \text { significant lower compared to other group; (e) } \\
\text { significantly compared to epidural group ; (w) significantly compared to water group ; (n) significantly } \\
\text { compared to normal saline group. }\end{array}$} \\
\hline
\end{tabular}

Regarding the mean arterial blood pressure, our study showed significant difference between all groups as shown in table (3). There was a significant decrease in mean arterial blood pressure after 5 min in sterile water group compared to other groups. Furthermore, there was significant decrease in mean arterial blood pressure in epidural group compared to normal saline control group after 15 minutes while it was not significant after 5 minutes (Table 3 ).

Table (3): Comparison between groups according to mean arterial BP after injection.

\begin{tabular}{|c|c|c|c|c|}
\hline & group I & group II & group III & \\
\cline { 1 - 3 }
\end{tabular}


ejhm.journals.ekb.eg

\begin{tabular}{|c|c|c|c|c|c|c|c|}
\hline & Mean & Std. Deviation & Mean & $\begin{array}{c}\text { Std. } \\
\text { Deviation }\end{array}$ & Mean & $\begin{array}{c}\text { Std. } \\
\text { Deviation }\end{array}$ & P.VALUE \\
\hline Pre Inject & 105.25 & \pm 3.193 & 105.78 & \pm 2.991 & 106.08 & \pm 3.377 & $<0.005$ \\
\hline BP 5 MIN & 95.20 & \pm 2.766 & 81.45\#en & \pm 2.342 & $104.23 * \mathrm{w}$ & \pm 2.896 & $<0.005$ \\
\hline BP $10 \mathrm{MIN}$ & 87.93 & \pm 1.655 & $81.88 \#$ en & \pm 2.399 & $105.73 * \mathrm{w}$ & \pm 2.810 & $<0.005$ \\
\hline BP 15 MIN & $81.55 \# \mathrm{n}$ & \pm 2.062 & 81.23\#n & \pm 2.236 & $104.83^{*} \mathrm{ew}$ & \pm 2.745 & $<0.005$ \\
\hline BP 30 MIN & 81.43\#n & \pm 2.541 & 81.63\#n & \pm 2.415 & $104.70 *$ ew & \pm 3.421 & $<0.005$ \\
\hline BP 60 MIN & $81.83 \# \mathrm{n}$ & \pm 2.135 & $82.15 \# \mathrm{n}$ & \pm 2.045 & $104.75^{*}$ ew & \pm 3.119 & $<0.005$ \\
\hline BP 90MIN & $80.95 \# n$ & \pm 2.112 & $81.38 \# \mathrm{n}$ & \pm 2.559 & $105.30 *$ ew & \pm 3.502 & $<0.005$ \\
\hline BP120MIN & $80.95 \# \mathrm{n}$ & \pm 2.112 & $81.38 \# \mathrm{n}$ & \pm 2.559 & $105.30 *$ ew & \pm 3.502 & $<0.005$ \\
\hline BP150MIN & 81.70\#n & \pm 2.420 & $82.00 \# \mathrm{n}$ & \pm 2.364 & $104.68 *$ ew & \pm 2.990 & $<0.005$ \\
\hline BP180MIN & $81.30 \# n$ & \pm 2.255 & $80.58 \# n$ & \pm 2.147 & $105.38 *$ ew & \pm 3.078 & $<0.005$ \\
\hline
\end{tabular}

Data expressed as mean \pm SD. Group I (Epidural group). Group II (Sterile water group). Group III (Normal saline group)(*) significant higher compared to other group.(\#) significant lower compared to other group; (e) significantly compared to epidural group ; (w) significantly compared to water group ; (n) significantly compared to normal saline group.

Regarding the heart rate, our results showed significant difference between all groups as shown in table (3). There was a significant decrease in heart rate after $5 \mathrm{~min}$ in sterile water group compared to other groups. Furthermore, there was significant decrease in heart rate in epidural group compared to normal saline control group after 15 minutes while it was not significant after 5 minutes (Table 3 ).

Table (4): Comparison between groups according to heart rate after injection

\begin{tabular}{|c|c|c|c|c|c|c|}
\hline \multirow{2}{*}{ GROUPS } & \multicolumn{2}{|c|}{ group I } & \multicolumn{2}{c|}{ group II } & \multicolumn{2}{c|}{ group III } \\
\cline { 2 - 7 } & Mean & $\begin{array}{c}\text { Std. } \\
\text { Deviation }\end{array}$ & Mean & $\begin{array}{c}\text { Std. } \\
\text { Deviation }\end{array}$ & Mean & $\begin{array}{c}\text { Std. } \\
\text { Deviation }\end{array}$ \\
\hline $\begin{array}{c}\text { HR Pre } \\
\text { injection }\end{array}$ & 95.23 & \pm 3.416 & 94.75 & +2.994 & 94.83 & +2.943 \\
\hline HR 5 & 88.03 & \pm 1.510 & $72.73 \#$ \# & \pm 4.070 & $94.68 * \mathrm{w}$ & \pm 3.308 \\
\hline HR 10 & 82.70 & \pm 1.667 & $72.60 \#$ n & \pm 5.153 & $95.35^{*} \mathrm{w}$ & \pm 3.043 \\
\hline HR 15 & $72.98 \# \mathrm{n}$ & \pm 4.215 & $72.68 \# \mathrm{n}$ & \pm 4.654 & $95.40 * \mathrm{ew}$ & \pm 2.808 \\
\hline HR 30 & $73.53 \# \mathrm{n}$ & \pm 4.782 & $73.60 \# \mathrm{n}$ & \pm 4.018 & $94.60 * \mathrm{ew}$ & \pm 2.762 \\
\hline HR 60 & $72.20 \# \mathrm{n}$ & \pm 4.842 & $73.53 \# \mathrm{n}$ & \pm 4.772 & $94.70 * \mathrm{ew}$ & \pm 2.997 \\
\hline HR 90 & $72.78 \# \mathrm{n}$ & \pm 4.312 & $71.28 \# \mathrm{n}$ & \pm 4.523 & $95.15 * \mathrm{ew}$ & \pm 3.438 \\
\hline HR 120 & $72.33 \# \mathrm{n}$ & \pm 4.022 & $72.28 \# \mathrm{n}$ & \pm 4.987 & $94.65 * \mathrm{ew}$ & \pm 2.685 \\
\hline HR 150 & $72.95 \# \mathrm{n}$ & \pm 4.437 & $72.85 \# \mathrm{n}$ & \pm 4.365 & $94.48 * \mathrm{ew}$ & \pm 2.996 \\
\hline HR 180 & $70.83 \# \mathrm{n}$ & \pm 3.928 & $72.75 \# \mathrm{n}$ & \pm 5.222 & $95.03 * \mathrm{ew}$ & \pm 3.092 \\
\hline
\end{tabular}

Data expressed as mean \pm SD. Group I (Epidural group). Group II (Sterile water group). Group III (Normal saline group) (*) significant higher compared to other group.(\# ) significant lower compared to other group; (e) significantly compared to epidural group ; (w) significantly compared to water group ; (n) significantly compared to normal saline group.

Furthermore, our study showed significant difference between epidural group and other groups as shown in table (5). Regarding the complications, indeed, no complications were demonstrated in the $2^{\text {nd }}$ and $3^{\text {rd }}$ group. Nevertheless, 3 cases in the epidural group developed backache and received non-steroidal anti-inflammatory drugs for 10 days. Two cases developed mild pruritus with no need for treatment. One case developed shivering after $30 \mathrm{~min}$ and received $20 \mathrm{mg}$ pethidine.

Table (5): Comparison between groups according to complications.

\begin{tabular}{|c|c|c|c|c|}
\hline \multirow{2}{*}{ Groups } & Group E & Group SW & Group NS & \multirow{2}{*}{ P-value } \\
\cline { 2 - 4 } & Complications & complications & complications & \\
\hline
\end{tabular}


ejhm.journals.ekb.eg

\begin{tabular}{|c|c|c|c|} 
Number of cases & 6 & 0 & 0 \\
\hline Percent & $15 \% \%^{* *}$ & $0 \%$ & $0 \%$ \\
\hline
\end{tabular}

Data expressed as (n) and (\%).

** highly significant difference compared to other groups

Maternal satisfaction was demonstrated and compared between the groups. Table (6) showed highly significant difference between normal saline group and other groups as majority of cases showed excellent satisfaction in the epidural and sterile water group but in normal saline group the majority of cases showed poor satisfaction.

Table (6): Comparison between groups according to maternal satisfaction.

\begin{tabular}{|l|c|c|c|c|c|c|c|}
\hline $\begin{array}{c}\text { Maternal } \\
\begin{array}{c}\text { Satisfaction } \\
(\%)\end{array}\end{array}$ & \multicolumn{2}{|l|}{ Group E } & \multicolumn{2}{|l|}{ Group S.W } & \multicolumn{2}{|c|}{ Group N.S } & \multirow{2}{*}{ P-VALUE } \\
\cline { 2 - 8 } & Frequency & Percent & Frequency & Percent & Frequency & Percent & \\
\hline Excellent & 30 & $75 \%$ & 25 & $62.5 \%$ & 0 & $0 \% * *$ & $<0.001$ \\
\hline Good & 10 & $25 \%$ & 12 & $30 \%$ & 0 & $0 \% * *$ & $<0.001$ \\
\hline Fair & 0 & $0 \%$ & 3 & $7.5 \%$ & 12 & $30 \% \%^{* *}$ & $<0.001$ \\
\hline Poor & 0 & $0 \%$ & 0 & $0 \%$ & 28 & $70 \%^{* *}$ & $<0.001$ \\
\hline
\end{tabular}

Data expressed as frequency and percentage

** Highly significant difference compared to other groups

\section{DSCUSSION}

Central neuraxial blockade in labor in the form of walking epidurals is routinely practiced in many institutions. However, central neuraxial blockade has certain absolute and relative contraindications and in patients where it cannot be offered one must know what other modalities of labor analgesia can be used in the best interest of the patient. Uterine contractions are felt as back pain because rami of T10- L1 supplying the uterus are also supplying the skin over the lumbosacral area ${ }^{(9)}$.

Many studies showed that epidural analgesia was associated with increased number of cesarean delivery. However increased use of epidural analgesia did not change the overall dystocia and cesarean delivery rate where dystocia was more common with epidural anesthesia ${ }^{(10)}$.

In our study, instrumental delivery was more in epidural group than other groups but nonsignificant statistically (Table 1). In another study done to 20 women had sterile water injection (SWI) against placebo showed that sterile water injection was effective as analgesic with few side effects. About 4 women complained of pain of injection but the pain associated with the injection of sterile water was weighed against the likelihood of rapid, effective pain relief. So, the net result showed satisfaction on $95 \%$ of cases. Some maternity practitioners advocated administering the injections during a uterine contraction to mitigate the intensity of the pain. Additionally, SWIs can be administered at any time during labour, including early labour ${ }^{(11)}$.
In our study, VAS started to reduce to significant level in sterile water group within $5 \mathrm{~min}$ and in the epidural group within 15 min (Table 2). Another double-blinded, placebo-controlled trial had been done, where sixty laboring patients were randomly allocated into one of two groups. Group I (40 patients) received four injections of sterile water while group II (20 patients) received four injections of normal saline as a placebo intracutaneous to Michaelis' rhomboid during active first stage of labor. Pain scores were similar between both groups at time of injections but significantly lower at 10, 45 and 90 minutes in group I compared to group II, with maximal difference at 10 minutes following injections. Also, participants requesting more pain relief were more among group II with a statistically significant difference. Moreover, significantly more participants of group I accepted this technique to be used in their future labors ${ }^{(\mathbf{1 2})}$.

Our study showed significant difference between epidural group and other groups regarding the complications. Indeed, no complications were demonstrated in the $2^{\text {nd }}$ and $3^{\text {rd }}$ group. Nevertheless, 3 cases in the epidural group developed backache and received non-steroidal anti-inflammatory drugs for 10 days. Two cases developed mild pruritus with no need for treatment. One case developed shivering after $30 \mathrm{~min}$ and received $20 \mathrm{mg}$ pethidine.

Women in another study done to 20 women had sterile water injection against placebo largely viewed sterile water injections as an effective analgesia with few side effects. About 4 women complained of pain of injection but the pain associated with the injection of sterile water was 
ejhm.journals.ekb.eg

weighed against the likelihood of rapid and effective pain relief. So, the net result showed satisfaction on $95 \%$ of cases. Some maternity practitioners advocated administering the injections during a uterine contraction to mitigate the intensity of the pain. Additionally, SWIs can be administered at any time during labour, including early labour (12).

One of the disadvantages of dermal injection of sterile distilled water is feeling pain at the site of injection for 20-30 sec as a result of which women may refuse re-injection. This pain probably results from the creation of high osmotic pressure in the skin and edema in the superficial layers. To reduce the pain in the injection area while retaining the effectiveness, several modifications in the injection technique should be studied. We chose a single bolus based on body weight, however, in clinical practice, some may prefer to titrate intra venous (IV) drugs to affect. Thus, our results cannot be compared to other studies with repeated doses or IV infusion. In Hosseini et al. ${ }^{(13)}$ study, the use of subcutaneous injection of sterile distilled water has been proposed as an alternative to intracutaneous injection due to its lower rate of pain. They, showed that substitution of intradermal injection with subcutaneous injection of sterile distilled water was better outcomes regarding pain of injection. Other recent study also, recommend using the technique of intradermal injection at time of uterine contraction, either to reduce the effect of the stinging sensation or to mask differences between the sterile water and normal saline solutions, which is associated with markedly less pain. Moreover, women also expressed a preference for receiving the injections during a contraction ${ }^{(\mathbf{1 4})}$. Choudhary and East ${ }^{(15)}$ showed that sterile water group patients were visibly happier after receiving the intradermal injection and the effectiveness increased when used as part of multimodal analgesia as paracetamol.

In our study, women were very satisfied with this technique and declared that they will use it again, although $96 \%$ indicated good satisfaction, where in our study maternal satisfaction was better in epidural and sterile water as compare to normal saline group. However, there is a fact must be carefully explained to the women that like other pain relief measures, it may not be $100 \%$ effective or last for hours but it can be repeated, also it may be an option for women who do not want to use narcotics or who refuse to have an epidural.

\section{CONCLUSION}

The evidence from this study suggests that sterile water injections are safe and effective method to relieve pain in the 1st stage of labor similar to epidural bupivacaine analgesia. Additionally, it is simple and safe technique and is associated with women satisfaction, which may provide women with an alternative method to narcotics and epidurals.

\section{References}

1. Hoy D, Brook P, Blyth F et al. (2010): The epidemiology of low back pain. Best Pract Res Clin Rheumatol., 24: 769-81.

2. Harms-Ringdahl K (2012): How should we use the visual analogue scale (VAS) in rehabilitation outcomes III: on the validation requirements for assessments using VAS with ratio properties. J Rehabil Med., 44 (9): 8012.

3. Anim S M, Smyth R, Howell C (2018): Epidural versus non-epidural or no analgesia for pain management in labour. DOI: 10 . $1002 / 14651858$.

4. Carroll JK, Cullinan E, Clarke L et al. (2012): The role of anxiolytic premedication in reducing preoperative anxiety. British Journal of Nursing, 21 (8): 479- 483.

5. Rezak A, Munir T, Ismael MM et al. (2012): Intradermal injection of sterile water versus epidural bupivacaine in painless labor. http://www.aamj.eg.net/inner/jarticle.a $\operatorname{spx}$ ?aid=1759

6. Senel AC, Mergan F (2014): Premedication with midazolam prior to caesarean section has no neonatal adverse effects. Braz J Anesthesiol., 64: 16-21.

7. Eltzschig H, Lieberman E, Camann W (2003): Regional anesthesia and analgesia for Labor and delivery. N Engl J Med., 348: 31932.

8. Hutton EK (2009): Sterile water injection for labour pain: a systematic review and meta-analysis of randomised controlled trials. BJOG: An International Journal of Obstetrics \& Gynaecology, 116 (9): 11581166.

9. Choudhary N, Saxena KN, Wadhwa B (2018): Labor analgesia with intradermal sterile water block in a patient with dilated cardiomyopathy. Journal of Obstetric Anaesthesia and Critical Care, 8 (2): 96-103.

10. Carroll JK, Cullinan E, Clarke L et al. (2012): The role of anxiolytic premedication in reducing preoperative anxiety. British Journal of Nursing, 21 (8): 479-483. 


\section{ejhm.journals.ekb.eg}

11. Lee N, Kildea S, Stapleton H (2017): "No pain, no gain": The experience of women using sterile water injections. Women and Birth, 30 (2): 153-158.

12. Farag A, Khaled M, Mohammed $M$ (2015): Intracutaneous sterile water injections for relief of back pain during labor. Med J Cairo Univ., 83 (1): 401-8.

13. Hosseini L, Najar S, Haghighizadeh MH (2010): Effect of subcutaneous injection of isotonic, sterile water, labour pain, type of labour and satisfaction with pain management in nulliparous women. Hayat J., 16: 41-7.

14. Rai R, Uprety D, Pradhan T et al. (2013): A randomized controlled trial. NJOG., 8 (2): 68-70.

15. Costley P, East C (2013). Oxytocin augmentation of labour in women with epidural analgesia for reducing operative deliveries. https://www.ncbi.nlm.nih.gov/p ubmed/22592738 